\title{
Improving Skills for School Children
}

\author{
Ioan Grosu ${ }^{1,2,3, *}$ \\ ${ }^{1}$ Rehabilitation Department, Apollonia University, Iasi, Romania \\ ${ }^{2}$ Faculty of Medical Bioengineering, University of Medicine and Pharmacy Gr.T.Popa, Iasi, Romania \\ ${ }^{3}$ Chemistry Department, Alexandru Ioan Cuza University, Iasi, Romania \\ *Corresponding author: ioan.grosu@chem.uaic.ro
}

Received January 24, 2014; Revised February 17, 2014; Accepted March 03, 2014

\begin{abstract}
It is suggested that the use of technical enough toys by school children help them to improve their practical skills. One of such toys is Driven Spinning Top as a modified version of the old and much beloved Spinning Top. Preliminary results report just positive effects. Other such toys should be invented, adapted or adopted.
\end{abstract}

Keywords: practical skills, gender gap, science education, primary school, toys, spinning to, driven spinning top

Cite This Article: Ioan Grosu, "Improving Skills for School Children." American Journal of Educational Research, vol. 2, no. 3 (2014): 135-137. doi: 10.12691/education-2-3-3.

\section{Introduction}

Today mostly every country pays an increased attention to Education and Science and Technology as a reliable sources of progress. European Union released on Nov. $20^{\text {th }}, 2012$ a document RETHINKING EDUCATION [1] to push Education in direction of improving skills in order to lower the unemployment rate among young people. Practical skills are needed for a balanced development of children and further for becoming qualified workers for sophisticated operations.

In these digital times children are busy and fond of the new electronic facilities. This is a great acquisition of the recent times. However any abuse is dangerous or in other words neglecting the natural activities as sport, playing with real life three-dimensional toys could have negative effects. Recently we heard several complaints from primary school teachers concerning the elementary skills of their school children. Just clicking with the mouse or touching screens is not enough for a healthy, balanced activity of school children. A recent book develops this topic [2].

In this paper we suggest an idea which can help to diminish these difficulties. It is about a didactic device and toy invented in Romania [3] and produced by REKUBUS in Germany [4] under the commercial name TOPSPEEDY.

The Spinning Top (ST) is a much beloved and old toy known all over the world ; it has different names in 109 languages but every child or adult knows it /5/. Its magic comes from the vertical position when it rotates. When rotation ceases it lies on one side. The explanation is from the conservation of angular momentum a nice principle in Physics. However this famous toy has a terrible defect: it can not be driven in a desired direction. We like to say that mankind used ST more than 2000 years but it did whatever it wanted paying no care to the experimenter or once put into rotation it behaved in an uncontrollable manner. From our experience of teaching Physics at the university level it came the idea of making this toy controllable. A controllable Spinning Top is called Driven Spinning Top (DST) and will be presented in the next section.

DST is very different from the other toys (no wonder because comes from an idea from Physics). Playing with it improves patience, coordination hand-eye, perseverance. It is magic, interactive, educative and scientific for all ages. Section 3 contains discussions of the preliminary results. Being a novelty not many people had the chance to use it. DST did not say the last word. It is expected to be used, modified, optimized for different ages. It could be even a therapeutic toy. The paper ends with Conclusions.

\section{Driven Spinning Top}

In all handbooks of Physics and Chemistry is written that the nuclear spin has a precession motion around the external magnetic field (when a semi classical interpretation of the Nuclear Magnetic Resonance (NMR) is discussed). This is not intuitive at all. In 1985 we modified a classical gyroscope by putting 2 permanent magnets on its axis. Such a modified gyroscope placed in a coil supplied with a direct current shows a Larmor precession [6]. We adapted this idea to the ST [3,7]. We put a small cylindrical permanent magnet on the axis of a ST, at its top end. A $2^{\text {nd }}$ bigger permanent magnet is put in a piece of wood and can be used as a driver when is kept vertical in hand above the ST and is moved slowly in any horizontal direction. This modified ST and the driver is the new DST $[3,7,8]$. In the following we will observe that DST is qualitatively superior to classical ST. Actually DST is the ST of the $21^{\text {st }}$ Century [9]. A second modification is a cylindrical piece of metal inside the body of the ST to increase the moment of inertia and to obtain longer times of rotation up to 110 seconds. A third 
modification is a ball of iron above the $1^{\text {st }}$ permanent magnet on the axis of ST. When the driver is too close to ST then they stick together and the ball is between the two magnets and the rotation continues because the contact is point-like.

All these 3 modifications can be recognized by watching the video [10]. At the bottom of the frame the current time (ct) is posted. The total time is 3:19 (3 minutes and 19 seconds). In the following we discuss the video moments by noting the different current times(ct). At $\mathrm{ct}=8-10$ we observe how the ST is put into rotation. The stick of the ST has to be rolled along between the 2 hands. This is the most difficult operation. Some succeed at once others need some time to get the skill to do it. The second secret of a good use is to observe that to drive ST it is needed to keep the driver vertical above the ST and to move it slowly. This looks like a defect but it is an advantage because helps to improve patience. Other toys encourage violence. The ST does not follow the driver if it is moved quickly, it means that the player should have patience to move it slowly. With such a toy several games can be played ( $\mathrm{ct}=0: 45-2: 14)$. DST can be stuck on the driver and by shaking hand it is released on the table still rotating $(\mathrm{ct}=1: 03-1: 09)$. For $\mathrm{ct}=1: 21-1: 40$ and $\mathrm{ct}=1: 46-2.14$ and $\mathrm{ct}=2: 20-2: 34$ DST is moved on different itineraries with points for competitions. For $\mathrm{ct}=3: 04-3: 10$ DST is transported in a certain place still rotating. All these are technical novelties at least in comparison with the classical ST or other toys. Playing a competition the child [11] in his/her desire to gain more points improves his/her patience, self-confidence, coordination hand-eye and practical skills. At $\mathrm{ct}=0: 42$ when the two magnets stick together with the DST keeping rotation is a new technical solution (a joint with 2 degree of freedom). At $\mathrm{ct}=2$ :432:50 a second new technical solution with a chain of two rotating DSTs.

\section{Discussions}

The DST presented above is a educational toy technical enough and easy to be used by both girls and boys. Other toys like this could be imagined, adopted, adapted. The magic of the DST in addition to the magic of ST (its vertical position when is in rotation) is its driving. Everybody expects (from empirical experience) that the ST can not be driven. During the demonstrations we observed how people turn their heads, stop and look very puzzled at the DST. After a while they say :'I know, it's a magnet”. In fact there are 2 magnets because with one magnet can not be realized a driving. Another opinion from the public: "It does not stop? Does it keep rotating at infinit?". These observations come because the ordinary ST (that is operating with 3 fingers) rotates $15-20$ seconds and DST up to 110 seconds. Why such a difference is because DST contains in its body a metallic piece that increase the moment of inertia. So we like to say that DST has a challenge :"try and succeed". This is very important for a toy and a didactic device. We have just positive feedbacks. Everybody likes DST. Some can learn at once how to operate it others need some time. We know two extreme situations : a 5 years old boy tried 2 hours and a half in continuum getting progress at every try. Nobody could push him to continue or to impede him to stop trying. At the end he was so good that he could show how it works to other ones much older than him. His pride was bigger than him. On the opposite side a lady experienced teacher of Physics said "I will not try because I have two left hands". Conclusion: the little boy had the desire to succeed and he did it by many trial and error and the lady had already lack of self-confidence just to try. So skills can be improved by repetition. Once the progress is obtained the self-confidence is increased, the positive attitude is on and the self-esteem is increased. We learn from a very professional study on the role of motor activities in gaining self-esteem for school children [12]. Our above story about the 5 y.o. boy is an good example. Romanian Ministry of Education recommends DST for the use in schools in extracurricular activities for students of all ages with specific tasks for every age ( toy, toy and Physics, toy and Physics and Engineering ). If children use this toy then they will easier understand the precession involved in NMR (Nuclear Magnetic Resonance ). There are complaints that primary school teachers do not have a positive attitude to sciences [13]. It is normal to be like this : they need to be good at reading, arithmetic, at drawing, at music just to name the most important ones. Their education do not contains much sciences. Even if they teach some scientific words that are very strange for primary school students this does not mean that the problem is solved. By our opinion, at this age, the science education can be done by letting and helping them play technical enough toys[11,14,15]. If they do like this later they will have a good feeling of techniques, a positive attitude to sciences and no fear to try and to learn more. All the above discussions are useful too for the gender gap problem [16-22]. DST is an example that can be used when it is explained the term knowledge-based economy: it is good to observe phenomena, to record them, to measure some properties of them but it is better when we can control them. ST was used more than 2000 years but now it can be controlled and this idea came from Physics. The school children that use DST will understand better and deeper (in their university studies) the Physics of NMR or MRI (Magnetic Resonance Imaging ) or fMRI(functional MRI) as modern tools in today health care. Several projects are on the way. Very recently a primary school teacher wrote [24] "DST has very positive effects on children developing their motor abilities and skills. More than this my own son was cured by some deficiencies in writing that I could not correct with other methods". Similar results come from a class of students with special needs [25].

\section{Conclusions}

The use of technical enough toys $[14,15]$ in extra curricular or even curricular activities by school children in their activities can prevent the lack of elementary skills. DST is one of these toys. DST is challenging enough that increase the well being of children that improves the efficiency of learning.

\section{List of Abbreviations}

ST-Spinning Top 
DST-Driven Spinning Top

NMR-Nuclear Magnetic Resonance

MRI-Magnetic Resonance Imaging

fMRI -functional MRI

\section{Acknowledgement}

The feedbacks from Maria Botos, Satu Mare and Adina Tulbure, Constanta are highly appreciated.

\section{References}

[1] http://ec.europa.eu/education/news/rethinking_en.htm.

[2] Spitzer, M., Digitale Demenz, Droemer Verlag, Muenchen, 2012.

[3] Grosu, I., Toy with controlled dynamics (in Romanian ): Patent RO122019/28.11/2008.

[4] TOP SPEEDY, http://www.rekubus.eu/top-speedy, have been accessed on Jan. $18^{\text {th }} 2014$.

[5] Museum of Tops, http://www.topmuseum.org has been accessed on Jan. $18^{\text {th }} 2014$.

[6] Grosu, I., Didactic device for obtaining Larmor (in Romanian) Patent RO91857/28.02.1987.

[7] Grosu, I., Driven Spinning Top: Patent China ZL200680055182.6 /23.05.2012.

[8] Grosu I, Driven Spinning Top, http://patentscope.wipo.int/search/en/WO2008002167.

[9] Science-on Stage video, Copenhagen, April 2011, http://www.youtube.com/watch?v=RCk9A4jqdtI\%2F but the link does not work at the moment.

[10] TOP SPEEDY video, http://www.youtube.com/watch?v=LauHISuq_ms\&feature=player _embedded/.

[11] a video playing with DST: http://www.youtube.com/watch?v=Vpo_T8sq2SM.
[12] Valentini, M., Di Massa, E., Troiano,G., Federici, A., The Role of Motor Activity in the Self-Esteem of Primary School Pupils, American Journal of Educational Research 2013, 1(2), 37-40.

[13] Van Aalderen-Smeets, S., Van der Molen, J.H.Walma, Asma, L.J.F., Primary Teachers Attitudes Toward Science: A New Theoretical Framework, Science Education 2012, 96(1), 158-182.

[14] Featonby, D., Toys and physics, Phys. Educ. 2005, 40.537.

[15] Featonby, D., Dare we teach tops ?, Phys. Educ. 2010, 45, 409

[16] Efuwape, B.M., Aremu, A., "Gender Differences in Acceptability and Usability of Computer Based Learning Package in Electrical and Electronics Technology in Nigeria “, American Journal of Educational Research. 2013, 1(10), 419-424.

[17] Madsen, A., McKogan,S.B., Sayre, E.C.,” Gender Gap on concept inventories in physics :What is consistent, what is inconsistent and what factors influence the gap “, Phys. Rev. ST Phys. Educ. Res. 2013, 9, 020121.

[18] Lorenzo,M., Crouch,H.C., Mazur,E.,” Reducing the gender gap in physics classroom”, Am.J. Phys. 2006, 74(2), 118-122.

[19] Grosu, I., Science :it's a girl thing should start with adequate toys, Open Journal of Education 2013, 1(5), 139-142,

http://manuscript.sciknow.org/uploads/oje/pub/oje_1369821921.p df.

[20] RoTop_1of3_1st_Try.avi, available to http://www.youtube.com/watch?v=M_aW-kazto\&feature=related/, have been accessed on May 25 th 2013.

[21] RoTop_2of3_Just_Play.avi, have been accessed on May 25 th 2013, available to

http://www.youtube.com/watch?v=N2byaiPlxno\&feature=related/.

[22] RoTop_3of3_Expert_Mode.avi, have been accessed on May 25 th 2013, available to http://www.youtube.com/watch?v=GNtcBDsONSU\&feature=relat ed/.

[23] Aswad, N.G., Vidican, G., Samulewicz, D., “Creating a knowledge-based economy in the United Arab Emirates : realizing the unfulfilled potential of women in science, technology and engineering fields", European Journal of Engineering Education 2011, 36:6, 559-570.

[24] Tulbure, A., private communication.

[25] Botos, M., private communication. 